\title{
LA ENSEÑANZA DE LA HISTORIA EN LAS FILIPINAS ESPAÑOLAS A TRAVÉS DE LOS LIBROS DE TEXTO: NEGOCIO, CENSURA Y CONTROL SOCIAL*
}

\section{Textbooks and the teaching of history in the Spanish Philippines: business, censorship and social control}

\section{Juan Antonio Inarejos Muñoz ${ }^{\varphi}$}

Fecha de recepción: 02/10/201 • Fecha de aceptación: 25/01/2018

Resumen. El contenido y enfoque de las asignaturas de historia recogidas en la reforma de la Instrucción Primaria de Filipinas de 1863 fueron concebidas por las autoridades coloniales como un efectivo mecanismo de control social. Por eso los libros de texto destinados a la enseñanza primaria y secundaria estuvieron sometidos al férreo control y a la censura de los religiosos que controlaron la educación colonial. Pero esta reforma educativa también abrió enormes horizontes de enriquecimiento económico a través del negocio de la venta de los libros de texto destinados a las instituciones educativas filipinas encuadrados en la tradición historiográfica liberal conservadora. Finalmente, durante el tramo finisecular, cuando arreciaron las protestas contra el dominio peninsular en el archipiélago, las autoridades coloniales apoyaron la distribución como manuales escolares de una serie de obras de carácter patriótico que ensalzaron la obra colonizadora de la metrópoli.

Palabras clave: Historia; Educación; Enseñanza de la historia; Libros de texto; Filipinas

Abstract. The content and focus of the history subjects contemplated in the reform of the Primary Instruction of the Philippines of 1863 were conceived by the colonial authorities as an effective mechanism of social

\footnotetext{
* Trabajo realizado en el marco del proyecto nacional de investigación financiado por el MINECO titulado «Replanteamiento de la política colonial española en el siglo xIx: la modernización de Filipinas, 1868-1898» (HAR2015-66511-P).

${ }^{\varphi}$ Departamento de Didáctica de las Ciencias Sociales, Lengua y la Literatura. Facultad de Formación del Profesorado, Universidad de Extremadura. Avenida de la Universidad s/n, 10003
}

Cómo citar este artículo: Inarejos Muñoz, Juan Antonio. «La enseñanza de la Historia en las Filipinas españolas a través de los libros de texto: negocio, censura y control social». Historia y Memoria de la Educación 8 (2018): 527-548. 
control. That is why textbooks destined for primary and secondary education were subject to the tight control and censorship of the religious authorities in charge of colonial education. But this educational reform also opened enormous horizons of economic enrichment through the business of selling textbooks intended for Philippine educational institutions in the framework of the conservative liberal historiographical tradition. Finally, during the final years of the century, when the protests against peninsular domination in the archipelago increased, the colonial authorities supported the distribution in the form of school manuals of a series of markedly patriotic works that extolled the colonizing work of the metropolis.

Keywords: History; Education; History Teaching; Textbooks; Philippines

\section{INTRODUCCIÓN}

La aprobación del Decreto de Instrucción Primaria de Filipinas en diciembre de 1863, un apéndice colonial de la Ley de Instrucción Pública de 1857, marcó un importante hito en la evolución educativa del archipiélago asiático. ${ }^{1}$ Por un lado sentó las bases del crecimiento exponencial que experimentaron la escolarización y la alfabetización de la población insular ampliando la inicial labor desarrollada por las escuelas parroquiales y las instituciones religiosas prácticamente desde los tiempos de la conquista. ${ }^{2}$ Junto al énfasis en la espinosa cuestión del impulso del castellano, la normativa también recogió la meticulosa organización de los planes de estudio y de las asignaturas. Así ocurrió con las asignaturas de historia que cursaron los varones, Historia de

\footnotetext{
${ }^{1}$ Carlos Isabel, «El Plan de Instrucción Pública para Filipinas de 1863 y sus orígenes en la legislación educativa española», Revista Filipina 2, no. 1 (2014): 25-36. Consultado el 10 de junio de 2017. http:// revista.carayanpress.com.

${ }^{2}$ Para ampliar los orígenes del sistema educativo colonial en Filipinas, véanse las clásicas obras de Camilo Osias, Education in the Philippine Islands under the Spanish regime (Manila: Philippine Education Company, 1917); Encarnación Alzona, A history of education in the Philippines, 1565-1930 (Manila: Universidad de Filipinas, 1932); Evergisto Bazaco, Escuelas normales y de enseñanza media en Filipinas (Manila: Imprenta de la Universidad de Santo Tomas, 1953); Evergisto Bazaco, History of Education in the Philippines (Manila: Universidad de Santo Tomás, 1953); Frederick Fox, «Primary education in the Philippines, 1565-1863», Philippine Studies 13, no. 2 (1965): 207-231; Dalmacio Martin (ed.), A century of education in the Philippines (1861-1961) (Manila: Philippine Historical Association, 1980); Antonio M. Molina, «Filipinas», en Historia de la Educación en España y en América. Volumen 3. La educación en la España contemporánea (1789-1975), coord. Buenaventura Delgado Criado (Madrid: Fundación Santa María, 1993), 508-513.
} 
España e Historia de Filipinas, sustituidas por Trabajo industrial femenino en el caso de las niñas. ${ }^{3}$

El contenido y enfoque de estas asignaturas fueron concebidas por las autoridades coloniales como un efectivo mecanismo de control social y un potente instrumento nacionalizador. Por eso los libros de texto destinados a la enseñanza primaria y secundaria estuvieron sometidos al férreo control y a la censura de la todopoderosa Comisión de Instrucción Primaria de Filipinas dominada por los religiosos. ${ }^{4}$ En definitiva, las mismas autoridades que vieron con recelo el impulso del castellano como posible puerta de entrada de ideas anticlericales que pusieran en entredicho las extensos espacios de poder atesorados en la colonia asiática, enrocados frente a los intentos por modernizar y secularizar la enseñanza en el último tercio del siglo xix impulsados por ministros como Segismundo Moret o Manuel Becerra. ${ }^{5}$

\section{DE LA SELECCIÓN DE LOS MAESTROS AL CONTROL DE LOS LIBROS DE TEXTO DE HISTORIA}

El Reglamento de la Escuela Normal de Maestros de Instrucción primaria de indígenas de las Islas Filipinas recogió, entre los requisitos que debían reunir los aspirantes a maestro, «Haber observado buena conducta y acreditarlas con certificaciones del Jefe de la provincia y Cura párroco del pueblo de su naturaleza o domicilio». ${ }^{6}$ Unos informes de conducta similares a los requeridos a los aspirantes a ostentar el cargo de gobernadorcillo, a grandes rasgos asimilables a los alcaldes peninsulares. Alcaldes y maestros fueron un pilar decisivo de la dominación colonial, una trascendencia que se desprende del interés que prestaron las autoridades

\footnotetext{
${ }^{3}$ El decreto, en Ministerio de Ultramar, Real decreto estableciendo un plan de instrucción primaria para Filipinas (Madrid: Imprenta Nacional, 1864), disponible en línea, URL: http://www.bne.es/es/ Catalogos/BibliotecaDigitalHispanica/Inicio/index.html

${ }^{4} \mathrm{Al}$ igual que ocurrió con el resto de publicaciones y la prensa insular: Juan Antonio Inarejos Muñoz, «La prensa decimonónica filipina: de la censura a soporte revolucionario», en Redes de comunicación: la prensa en el mundo hispánico, coord. Henriette Pratz (Berlin: Frank and Timme, 2016), 199-212.

${ }^{5}$ Julia Celdrán Ruano, Instituciones Hispanofilipinas del siglo XIX (Madrid: MAPFRE, 1994); Manuel Sarkisyanz, Rizal and Republican Spain and other Rizalist Essays (Manila: National Historical Institute, 1995); y M. ${ }^{a}$ Dolores Elizalde Pérez-Grueso (ed.), Repensar Filipinas. Política, Identidad y Religión en la construcción de la nación filipina (Barcelona: Bellaterra, 2009).

${ }^{6}$ Ministerio de Ultramar, Real decreto estableciendo un plan de instrucción primaria para Filipinas (Madrid: Imprenta Nacional, 1864).
} 
metropolitanas a la hora de seleccionarlos. ${ }^{7}$ Baste recordar la minuciosidad del sugerente informe presentado por el Gobernador Político-Militar de Abra del aspirante más votado en las elecciones de gobernadorcillo celebradas en el pueblo de Pilar el 8 de abril de 1895:

En la actualidad posee escasos bienes de fortuna en el pueblo, sin que tenga otros medios de vivir según antecedentes en este Gobierno que su profesión de maestro, incompatible con el cargo de gobernadorcillo. Sus antecedentes de carácter díscolo, así como su conducta política no le hacen recomendable a este Gobierno. ${ }^{8}$

La educación, además de ser un importante instrumento de poder, también abrió numerosas posibilidades de enriquecimiento económico a través del negocio de la elaboración y venta de los libros de texto destinados a las instituciones educativas filipinas. ${ }^{9}$ La aplicación del Decreto dio lugar a una cascada de solicitudes para lograr de las autoridades coloniales la autorización para introducir libros de texto de las distintas asignaturas en las escuelas insulares. En relación a la enseñanza de la historia, una de las primeras solicitudes fue elevada por Manuel Ibo Alfaro, autor de obras como Resumen de la Historia de España o Compendio de Historia Universal, para las que demandó el beneplácito para ser distribuidas en la colonia asiática. Como argumento a su favor alegó que ambas obras habían sido declaradas libros de texto en la metrópoli:

Que siguiendo V. E. la práctica de algunos capitanes generales de esas islas y considerando que dichas obras contienen todas

\footnotetext{
${ }^{7}$ La elaboración de una prosopografía de los aspirantes seleccionados por las autoridades para el cargo de maestro, que desborda los objetivos de este artículo, es otra de las aristas que reclama nuevos estudios.

${ }^{8}$ Serie Elecciones de Gobernadorcillos, provincia de Abra, legajo 4, rollo 6368, Philippine National Archives (PNA). Se ha consultado la copia de este archivo albergada en la biblioteca Tomás Navarro Tomás del Centro de Ciencias Sociales y Humanas del CSIC (Madrid). Para las sanciones de los maestros considerados díscolos por las autoridades, véanse los trabajos de Grace Lisa Y. Concepción, "The Filipino primary school teacher and the shaping of colonial society in 19th century Luzon», International Journal of the Humanities 9, no. 6 (2012): 233-244; y «Disciplinary Cases of Filipino Teachers in the Late 19th Century», Social Science Diliman 10, no. 1 (2014): 1-27.

${ }^{9}$ El lucrativo negocio de la edición y distribución de manuales escolares en la colonia es otro de los asuntos que reclama nuevas investigaciones, apenas esbozado de forma tangencial en este artículo.
} 
las condiciones necesarias para la enseñanza, pues en tres trienios han sido declaradas texto en Madrid por tres Consejos de Instrucción Pública, de diferentes colores políticos, se digne V. E. expedir un decreto en uso de sus atribuciones declarando texto para la $2 .^{\circ}$ enseñanza en esas islas las dos citadas Historia Universal y de España. ${ }^{10}$

En su exposición, Manuel Ibo Alfaro subrayó el distinto color político de las administraciones que previamente habían autorizado la distribución de sus obras en la península. La solicitud fue elevada el 26 de noviembre, pocos meses después de que el progresista Carlos María de la Torre accediese al cargo de Gobernador General de Filipinas, ${ }^{11}$ cuyo mandato estuvo marcado por un mayor aperturismo y por sus intentos de aplicar las reformas impulsadas por las nuevas autoridades peninsulares. Los distintos colores políticos a los que hizo referencia Manuel Ibo Alfaro en su solicitud se referían a los partidos políticos «respetables» que ostentaron el poder durante el segundo tramo del reinado isabelino. Durante esta etapa este periodista, profesor, escritor y editor publicó una parte importante de sus obras, entre ellas las sometidas a aprobación por las autoridades insulares, escritos que alcanzaron un notable éxito editorial a tenor de las numerosas ediciones publicadas durante la segunda mitad del siglo xix. ${ }^{12}$ No obstante, dentro del abanico del liberalismo conservador destacó por su estrecha vinculación con O’Donnell y la Unión Liberal, como demuestran sus opúsculos La corona de laurel. Colección de biografías de los generales que han tomado parte en la gloriosa campaña de África (1860), y Apuntes para la historia de D. Leopoldo O'Donnell (1867; 2. ${ }^{\text {a }}$ ed. 1868), una semblanza hagiográfica del militar unionista que precisamente había hecho especial hincapié en la necesidad de impulsar la enseñanza del castellano en Filipinas durante la gestación del Decreto

\footnotetext{
${ }^{10}$ Serie Guerra, Subsección Orden Público, Legajo 8, rollo 1746, PNA. La solicitud fue elevada el 29 de noviembre de 1869.

${ }^{11}$ Antonio Caulín Martínez, «El mandato de Carlos María de la Torre (1869-1871): apoyo y oposición al primer gobernador enviado por la Gloriosa», en El Lejano Oriente Español: Filipinas (siglo XIX) (Sevilla: Cátedra General Castaños, 1997), 355-366.

${ }^{12}$ Sobre la dilatada producción literaria de Manuel Ibo Alfaro, véase Inmaculada Benito Argáiz, «Una aclaración necesaria en la bibliografía del escritor cerverano Manuel Ibo Alfaro (1828-1885)», Berceo 132 (1997): 7-28, y Julián Tomás Bravo (ed. lit.), Cuentos tradicionales y fantásticos: narrativa menor, artículos periodísticos, ensayos históricos y relatos breves de Manuel Ibo Alfaro (Logroño: Universidad de La Rioja, 2000).
} 
de Instrucción Primaria de $1863 .{ }^{13}$ En suma, el Duque de Tetuán había concebido estimular la enseñanza del castellano en la colonia como un arbotante más de su impulso al proceso nacionalizador que tuvo en las intervenciones coloniales una de sus principales espoletas:

En consecuencia, la Reina (q. D. g.) ha tenido a bien disponer recomiende a V. E. como de su Real orden lo verifico, que emplee todo el lleno de la Autoridad de que como Gobernador y Vice-Patrono está revestido para hacer que los curas, que en parte están encargados de la enseñanza primaria, consagren desde luego y muy especialmente su celo a difundir el conocimiento del idioma castellano, vigilando por todos los medios posibles para que así lo verifique, sin perjuicio de proponer al Gobierno todo lo que pueda ser conducente al logro de tan interesante objeto. ${ }^{14}$

La solicitud elevada por Manuel Ibo Alfaro consiguió pasar los tortuosos trámites y cribas de los distintos eslabones de poder. Inicialmente dirigida al Gobernador General, de esta autoridad pasó a la Comisión permanente de Censura, que aprobó su publicación y «circulación por el país» el 23 de marzo de $1870 .{ }^{15}$ Posteriormente fue remitida a la Universidad de Santo Tomás, cuyo Rector Domingo Treserra otorgó su beneplácito el 9 de mayo de 1870, aunque pidió que se compaginase con el texto en uso en ese momento, el Manual de Historia Universal de Alejandro Gómez Ranera. Ibo Alfaro también demandó que sus obras fuesen declaradas libros de texto, extremo que motivó que sus escritos tuviesen que pasar el filtro de la Comisión Superior de Instrucción Primaria, órgano que las aprobó el 9 de septiembre de 1870 después de contar con el informe del Director de la Escuela Normal. Finalmente, casi un año y medio

\footnotetext{
${ }^{13}$ Sobre las dificultades de implantar el castellano en Filipinas, véanse los trabajos de Vicente L. Rafael, Contracting Colonialism: Translation and Christian Conversion in Tagalog Society Under Early Spanish Rule (Durham: Duke University Press, 1993), y The Promise of the Foreign: Nationalism and the Technics of Translation in the Spanish Philippines (London/Durham: Duke University Press, 2005), así como de John David Blanco, Frontier Constitutions. Christianity and Colonial Empire in the Nineteenth-Century Philippines (Berkeley: University of California Press, 2009).

${ }^{14}$ Vicente Barrantes, La instrucción primaria en Filipinas, desde 1596 hasta 1868 (Madrid: Imprenta La Iberia, 1869), 106; disponible en línea, URL: https://books.google.com. El aliento insuflado al proceso nacionalizador durante los gobiernos unionistas, en Juan Antonio Inarejos Muñoz, Intervenciones coloniales y nacionalismo español. La política exterior de la Unión Liberal y sus vínculos con la Francia de Napoleón III (1854-1868) (Madrid: Sílex, 2010).

${ }^{15}$ Serie Guerra, Subsección Orden Público, Legajo 8, rollo 1746, PNA.
} 
más tarde, el 19 de enero de 1871, el Gobernador La Torre firmó la autorización para que fuese publicada en la Gaceta de Manila y se informase a las distintas autoridades. ${ }^{16}$

Desde el punto de vista historiográfico, las obras de Manuel Ibo Alfaro pueden encuadrarse en la tradición liberal conservadora decimonónica encabezada por Modesto Lafuente. ${ }^{17} \mathrm{El}$ inicio de la introducción de su Compendio de la Historia de España resultó sintomático: «P. ¿Qué es la historia de España?-R. La narración de los sucesos ocurridos en España desde la más remota antigüedad hasta nuestros días; cuyos sucesos son tenidos por verdaderos». ${ }^{18}$ En suma, una visión que interpretaba el pasado en clave nacional y situaba la existencia de España desde la noche de los tiempos, ${ }^{19}$ donde los pueblos prerromanos ya eran considerados como españoles: «P. Esplicarme (sic) las guerras de Viriato.-R. El Pretor Sergio Sulpicio Galva mató de la manera más indigna 9.000 españoles; entre algunos que lograron huir de esta traición se encontraba Viriato». ${ }^{20}$ Dentro de esta interpretación, la religión católica pasó a ser uno de sus principales arbotantes: «P. ¿Es útil el estudio de la historia?-R. Mucho; porque tanto el hombre en particular como las naciones en general, ven en ella el abismo en que se precipitaron los pueblos antiguos siempre que abandonaron el sendero de la verdadera religión». ${ }^{21}$ No resulta ca-

\footnotetext{
${ }^{16} \mathrm{Al}$ Director de la Escuela Normal, a la Comisión Superior, al Rector de la Universidad de Santo Tomás, al Provincial de San Agustín, al Provincial de San Francisco, al Provincial de Santo Domingo, al Superior de la Compañía de Jesús y al Gobierno Civil de la provincia de Manila.

${ }^{17}$ Modesto Lafuente, Historia General de España desde los tiempos más remotos hasta nuestros días. Discurso preliminar (Pamplona: Urgoiti, 1850-1858), edición de Juan Sisinio Pérez Garzón, 2002.

${ }^{18}$ Manuel Ibo Alfaro, Compendio de la Historia de España (Madrid: Establecimiento tipográfico de M. P. Montoya y Comp., 1863), ed. 1884, disponible en Biblioteca Virtual de La Rioja, consultado el 13-7-2017, URL: http://www.bibliotecavirtual.larioja.org/. La cita textual corresponde al resumen de esta obra, que no supone una variación cualitativa de la anterior; Manuel Ibo Alfaro, Resumen de la Historia de España (Madrid: Establecimiento tipográfico de los Sres. Martínez y Bogo, 1863), VII, disponible en Biblioteca Digital Hispánica, consultado el 13-7-2017, URL: http://www.bne.es/.

${ }^{19}$ Sobre los inicios de la historiografía nacionalista isabelina, véase Paloma Cirujano Marín, Juan Sisinio Pérez Garzón y Teresa Elorriaga Planes, Historiografía y nacionalismo español (1843-1868) (Madrid: CSIC, 1985).

${ }^{20}$ Manuel Ibo Alfaro, Resumen de la Historia de España (Madrid: Establecimiento tipográfico de los Sres. Martínez y Bogo, 1863), 14. En Biblioteca Digital Hispánica, consultado el 13-7-2017, URL: http://www.bne.es/.

${ }^{21}$ Manuel Ibo Alfaro, Resumen de la Historia de España (Madrid: Establecimiento tipográfico de los Sres. Martínez y Bogo, 1863), VIII. En Biblioteca Digital Hispánica, consultado el 13-7-2017, URL: http://www.bne.es/.
} 
sual que considerase «la espulsión (sic) de los árabes de España en el siglo XV» el acontecimiento que hace de gozne entre la Edad Media y la Edad Moderna. Desde el punto de vista de los protagonistas del pasado, la sucesión de reinados ocupa un lugar preeminente entre sus contenidos: «P. ¿Cuántos y cuáles fueron los reyes godos?-R. Treinta y tres, a saber: Ataulfo, Sigerico, [...]». ${ }^{22}$ Junto a epopeyas como el descubrimiento del Nuevo Mundo o de Filipinas, entre los acontecimientos más reseñados destacan las batallas y conquistas, particularmente aquellas libradas contra los musulmanes como la de las Navas de Tolosa, el sitio de Tarifa, la toma de Granada, Lepanto o la Guerra de África de la Unión Liberal, con la que finaliza la primera edición de la obra. ${ }^{23}$ En suma, únicamente aparece una testimonial referencia al descubrimiento de Filipinas en un manual que focaliza su atención en el devenir histórico metropolitano. Por su parte, el Compendio de Historia Universal estuvo marcado por su marcado carácter eurocéntrico sin referencias a la colonización del archipiélago asiático. ${ }^{24}$

Unos años después de la aprobación de los manuales de Ibo Alfaro se elevó una propuesta para sustituirlos por las obras tituladas Lecciones de historia universal y Nociones de historia universal elaboradas por Manuel de Góngora y Martínez. Estas obras fueron enviadas al Catedrático de Historia de segunda enseñanza de la Universidad de Santo Tomás, a quien ambas le parecieron «de verdadero mérito por su imparcialidad, corrección de estilo, exquisita crítica y muy particularmente por sus ideas sanísimas y su religiosidad». ${ }^{25}$ Pese a su favorable consideración, también admitió que no aportaban sustanciales ventajas para sustituir a las existentes. En su opinión, la primera de ellas era demasiado extensa para el periodo de tiempo tan corto de que se disponía para impartir esta

\footnotetext{
${ }^{22}$ Manuel Ibo Alfaro, Resumen de la Historia de España, 19.

${ }^{23}$ En las siguientes ediciones de esta obra, incluso posteriores a la muerte de su autor, se ampliaron las fechas del manual hasta los primeros años del siglo $\mathrm{xx}$ sin incorporar innovaciones cualitativas.

${ }^{24}$ Manuel Ibo Alfaro, Compendio de la Historia Universal (Madrid: Librería de la Viuda de Hernando y C. $\left.{ }^{\mathrm{a}}, 1891\right)$ 6. ${ }^{\mathrm{a}}$ ed. Disponible en Biblioteca Virtual de La Rioja, consultado el 1-7-2017, URL: http:// www.bibliotecavirtual.larioja.org/. Los últimos temas que se abordan en este manual hacen referencia a la Revolución francesa y al nacimiento de algunos estados europeos. La postrera y séptima edición de 1912 incorpora unos epígrafes narrando la emancipación de las colonias continentales americanas durante el primer tercio del siglo xIx; disponible en Biblioteca Digital Hispánica, consultado el 14-7-2017, URL: http://www.bne.es/.
}

${ }^{25}$ Serie Guerra, Subsección Orden Público, Legajo 8, rollo 1747 (rollo 33), PNA. 
asignatura, mientras que la segunda no tenía un pequeño tratado de Historia de España, como sí tenía la de Ibo Alfaro. Finalmente, el religioso aportó otra razón de peso a favor de las obras ya en uso: «que como esta viene sirviendo de texto hace tantos años, los estudiantes pobres, que no son pocos, pueden adquirírsela de valde o a bajo precio». ${ }^{26}$ Una vez conocido el dictamen de Fray Pedro Pérez, el Negociado de la Dirección General de Administración Civil pidió su opinión a la Comisión Superior de Instrucción Primaria. Esta instancia ratificó la opinión aportada por el primer religioso, lo que motivó que el Gobernador General desestimase la petición de Góngora para que sus obras fuesen declaradas libros de texto.

Al peso del argumento económico también habría que añadir las dificultades que tenían las librerías filipinas para proveerse de algunos libros de texto, particularmente los novedosos, según comunicó a las autoridades coloniales el Vicerrector del Ateneo Municipal de segunda enseñanza en 1877:

Siendo mi deber llamar la Superior atención sobre las dificultades que se encuentra aquí en concretarse a los autores señalados por el Gobierno; por no encontrarse las más de las veces en las librerías: por cuya razón ha sucedido estar señalada una obra oficial para un curso académico y tener que permitir a los discípulos comprar otras, por no serles posible proporcionarse la designada: otras veces sabiendo que para una asignatura no se encuentra en las librerías - los libros que el alumno debe llevarse-, han sido señaladas por necesidad otras que se encontraban aquí. Para obviar estas dificultades varios años se ha pasado con tiempo a las librerías nota de los libros que habían de servir en el curso académico que había de comenzar; y no siempre ha producido este efecto. Otros los ha traído el establecimiento por su cuenta, suponiendo no pocas dificultades. ${ }^{27}$

Para la segunda de las asignaturas recogidas en la legislación educativa, la de Historia de Filipinas, fueron aprobados libros de texto elaborados por los jesuitas que dirigían la Escuela Normal tras su vuelta al ar-

\footnotetext{
${ }^{26}$ Serie Guerra, Subsección Orden Público, Legajo 8, rollo 1747 (rollo 33), PNA.

${ }^{27}$ Serie Guerra, Subsección Orden Público, Legajo 8, rollo 1747 (rollo 33), PNA.
} 
chipiélago. ${ }^{28}$ En 1877 el Procurador general de la Compañía de Jesús de Filipinas, Luis Tello, solicitó que fuesen declarados libros de texto para las escuelas de primera y segunda enseñanza los compendios titulados Historia de Filipinas en preguntas y respuestas para los niños de las escuelas de primera enseñanza e Historia de Filipinas para los niños más adelantados, del jesuita Francisco Martín Luengo. La publicación de ambas obras ya había sido autorizada por la Junta de Censura. ${ }^{29}$ No obstante, para que fuesen declaradas manuales escolares debían contar también con la aquiescencia del Rector de la Universidad de Santo Tomás, quien afirmó: «las repetidas obritas vienen a llenar un vacío que se observa en las obras de texto de 2 . $^{\text {a }}$ enseñanza, por cuya razón deben ser consideradas como oportunas y sumamente útiles para la instrucción en estas islas». ${ }^{30}$ La Dirección General de Administración Civil también otorgó su beneplácito en 1877 hasta su ratificación formal por la Comisión Superior de Instrucción Primaria un año más tarde.

Desde el punto de vista pedagógico, la didáctica de la historia desplegada en clase estuvo marcada por su rigidez, el predominio de la memorización de datos y fechas y la hegemonía del libro de texto auxiliado por algún cuadro sinóptico:

Para este estudio bastarán algunos compendios metódicos de Historia, que el diestro Maestro acomodará á la comprensión de sus discípulos, aclarando ó ampliando lo que fuere conveniente: ayudarán á este estudio los cuadros sinópticos, que presentan en conjunto los hechos que han de estudiarse, así como el estudio de la Cronología y de la Geografía, que son como los ojos de la Historia. Para facilitar también dicho estudio servirá una buena colección de láminas, al modo que se usa en el estudio de la Historia sagrada. ${ }^{31}$

\footnotetext{
${ }^{28}$ Roberto Blanco Andrés, Entre frailes y clérigos. Las claves de la cuestión clerical en Filipinas (17761872) (Madrid: CSIC, 2012); James J. Meany, «Escuela normal de maestros», Philippine Studies 30, no. 4 (1982): 493-511.

${ }^{29}$ Serie Guerra, Subsección Orden Público, Legajo 8, rollo 1747 (rollo 33), PNA. La solicitud fue elevada el 28 de septiembre de 1877. También se solicitó la declaración de libro de texto de la Geografía de las Islas Filipinas, Marianas y Carolinas elaborada por el también jesuita Francisco Baranera.

${ }^{30}$ Serie Guerra, Subsección Orden Público, Legajo 8, rollo 1747 (rollo 33), PNA.

${ }^{31}$ Escuela Normal de Manila, Elementos de pedagogía para uso de los maestros de instrucción primaria de las Islas Filipinas (Manila: Tipo-litografía de Chofre y Cía, 1890), 65. Se puede consultar una versión de esta obra en la Biblioteca Digital Hispánica, URL: http://www.bne.es/. Sobre la didáctica
} 
León Salcedo, autor de la obra titulada Cuadro Sinóptico de las Islas Filipinas, también solicitó que su obra fuese declarada libro de texto para las escuelas de Instrucción Primaria de Filipinas. En 1873 la Junta Superior de Instrucción pública declaró que encontraba en esta obra «un poderoso auxiliar en el estudio de la historia y de la geografía, porque bajo un solo golpe de vista presentan toda la estructura y organización de la ciencia», dictamen que resultó decisivo para que el Gobernador de Filipinas aprobase su utilización en las escuelas de primera enseñanza. ${ }^{32}$ Incluso la Dirección General de Administración Civil autorizó que la adquisición de los ejemplares de esta obra fuese sufragada con fondos provinciales. ${ }^{33}$

Junto a esta serie de obras específicas para la colonia asiática, el Ministerio de Ultramar también autorizó un listado complementario de obras históricas, pedagógicas o patrióticas que podían ser utilizadas como manuales de texto en todas las provincias ultramarinas. ${ }^{34}$ Entre los títulos autorizados figuraron obras como las Lecciones de historia particular de España, de Rafael Rosas; el Compendio de Historia de España arreglado para la Instrucción Primaria, de Teófilo Jiménez; ${ }^{35}$ el Breve compendio de Historia de España, de Gabriel Román; Glorias de España, de Joaquín Nin y Tudó; la Cartilla pedagógica, de Ildefonso Estrada; El Patriotismo español, de Ramón Eliseo; y la Exposición de la Monarquía Española, de Manuel Valdez. ${ }^{36}$

Desde el punto de vista historiográfico, estas obras no albergaban diferencias sustanciales con el enfoque y contenido de los manuales de Ibo

empleada en las aulas filipinas, véase también Catalino Sevilla, «Memoria sobre los medios que deben ponerse en juego en Filipinas para atraer los niños a las escuelas por D. Catalino Sevilla. 1895», en Primer Certamen Pedagógico en Filipinas. Publicado por la Academia Pedagógica de Manila (Manila: Boletín Oficial del Magisterio Filipino, 1896), 23-39.

${ }^{32}$ Serie Guerra, Subsección Orden Público, Legajo 8, rollo 1747, PNA.

${ }^{33}$ Tras la consulta realizada por el Alcalde Mayor de Batangas, autoridad que solicitó 24 ejemplares de la citada obra por un total de 480 pesetas con cargo a la cantidad consignada en el presupuesto provincial para material de escuelas.

${ }^{34}$ Serie Guerra, Subsección Orden Público, Legajo 8, rollo 1747, PNA. El listado fue autorizado en 1887 por Víctor Balaguer, Ministro de Ultramar.

${ }^{35}$ Publicada en La Habana en la editorial Minerva. Se puede consultar una versión de la 8. a edición de esta obra en la Biblioteca Digital Hispánica, URL: http://www.bne.es/.

${ }^{36}$ La mayoría de estas obras fueron publicadas entre finales de los años setenta y la década de los ochenta en imprentas de La Habana. 
Alfaro. Baste recordar un fragmento de la obra de Teófilo Jiménez sobre las guerras lusitanas:

¿Cuál fue el origen de las guerras de Viriato? Que como el gobierno de la España romana fue encomendado a pretores, y éstos cometían toda clase de atropello, con los españoles, hasta el grado de hacer degollar el pretor Sergio Sulpicio Galva 9.000 españoles, Viriato, que era Lusitano, se puso a la cabeza de un puñado de valientes, con objeto de vengar tal felonía; y en ocho años que sostuvo la guerra alcanzó grandes victorias sobre los romanos. ${ }^{37}$

\section{COMBATIR LA CONTESTACIÓN CON MANUALES PATRIÓTICOS EN LAS ESCUELAS FINISECULARES}

En el tramo finisecular, cuando arreciaron las protestas contra el dominio peninsular en el archipiélago, ${ }^{38}$ las autoridades coloniales redoblaron su control sobre los libros de texto y autorizaron y apoyaron la distribución como manuales escolares de una serie de obras de carácter patriótico que ensalzaron la obra colonizadora de la metrópoli. En 1893 la Comisión Superior de Instrucción primaria autorizó la distribución anual como premio en los Institutos, Escuelas Normales e instituciones educativas filipinas de la obra titulada Romancero Filipino, del poeta Manuel Romero Aquino. El objetivo de esta adquisición se mostró sin ambages:

para difundir por este medio en el archipiélago, al propio tiempo que el conocimiento del idioma castellano el de las glorias patrias, considera dignos de los mayores respetos, tan levantados propósitos del Excmo. Sr. Gobernador General, con tanta más razón, cuanto que, elevados conceptos filosóficos como los de religión y patria, solo pueden inculcarse fácilmente en inteligen-

\footnotetext{
${ }^{37}$ Teófilo Jiménez, Compendio de Historia de España arreglado para la Instrucción Primaria (La Habana: Minerva, 1884), 10.

${ }^{38}$ En detalle, Magno Gatmaitan, The Life and Writings of Marcelo Hilario del Pilar (Manila: Historical Conservation Society, 1987); Hélène Goujat, Réforme ou Révolution? Le projet national de José Rizal (1861-1896) pour les Philippines (Paris: Éditions Connaissances et Savoirs, 2010); María Dolores Elizalde Pérez-Grueso (ed.), Entre España y Filipinas: José Rizal, escritor (Madrid: AECID/Ministerio de Asuntos Exteriores y de Cooperación, 2011).
} 
cias sencillas, como las de los habitantes de este país, por medio del ritmo cadencioso de sonoros versos que fácilmente percibidos por los órganos de la audición, retienen en el cerebro ideas, cuyas bellezas exigen, tiempo para poder ser apreciadas en la región serena del espíritu. ${ }^{39}$

El secretario de la Comisión de Instrucción pública no dudó en echar mano de los socorridos tópicos de la minoría de edad y de la supuesta inferioridad de los colonizados para justificar la presunta eficacia nacionalizadora de este tipo de obras ${ }^{40}$ un mecanismo similar a las herramientas que habían utilizado los primeros frailes para evangelizar con éxito el archipiélago:

No de otra manera nuestros primitivos misioneros grabaron en el corazón del indígena el augusto drama del Gólgota y a pesar del largo espacio de tiempo transcurrido desde la conquista espiritual de los habitantes de estas islas permanece aún arraigada entre sus naturales la costumbre de recitar en verso la pasión y muerte de Nuestro Señor Jesucristo ${ }^{41}$

La Dirección General de Administración Civil acordó el 15 de junio de 1893, una vez vistos los informes favorables de la Comisión de Instrucción pública, adquirir 10.000 ejemplares del Romancero Filipino con cargo al presupuesto provincial para distribuirlos entre las 2.143 escuelas existentes en el archipiélago en ese momento. Este compromiso además

\footnotetext{
${ }^{39}$ Serie Guerra, Subsección Orden Público, Legajo 8, rollo 1747, PNA. La Comisión de Instrucción primaria también indicó que su coste fuese sufragado por la Dirección General de Administración Civil con cargo al capítulo de material de enseñanza.

${ }^{40}$ Véase un análisis de estos prejuicios y lugares comunes empleados por los colonizadores en Luis Ángel Sánchez Gómez, Un imperio en la vitrina. El colonialismo español en el Pacífico y la Exposición de Filipinas de 1887 (Madrid: CSIC, 2003). Los inicios de la colonización en Filipinas, en John Phelan, The Hispanization of the Philippines. Spanish Aims and Filipino Responses, 1565-1700 (Madison: The University of Wisconsin Press, 2011) 1. ${ }^{a}$ ed. 1959; Luis Ángel Sánchez Gómez, Las principalías indígenas y la administración española en Filipinas (Madrid: Universidad Complutense, 1991); Patricio Hidalgo Nuchera, Encomienda, tributo y trabajo en Filipinas (1570-1608) (Madrid: Polifemo, 1995); William Henry Scott, Barangay: Sixteenth-century Philippine culture and society (Quezon City: Ateneo de Manila University Press, 1997); Luis Alonso Álvarez, «La Administración española en las islas Filipinas, 1565-1816. Algunas notas explicativas acerca de su prolongada duración», en Repensar Filipinas. Política, Identidad y Religión en la construcción de la nación filipina, ed. M. ${ }^{\mathrm{a}}$ Dolores Elizalde Pérez-Grueso (Barcelona: Bellaterra, 2009), 79-117.

${ }^{41}$ Serie Guerra, Subsección Orden Público, Legajo 8, rollo 1747, PNA.
} 
implicó la adquisición anual de un determinado número de ejemplares de esta obra. En 1896, tres años después de la primera autorización, la viuda de Manuel Romero Aquino, Felisa Garchitorena, demandó que ese año se adquiriesen 5.000 ejemplares de la obra de su difunto marido. ${ }^{42} \mathrm{El}$ libro de romances se había erigido en un mecanismo para socializar discurso patriótico nacionalista español, pero también era una importante veta para extraer recursos económicos.

En las páginas del prólogo de la obra, dedicada al entonces Gobernador de Filipinas, Eulogio Despujol, desgranó los elementos que el autor empleó a la hora de glosar las epopeyas de Magallanes y Elcano. Unos descubrimientos que a su vez permitían mantener activa la lucha en el plano religioso, exhortando a los mitos de la «Reconquista» y el mantenimiento del miedo al «turco» durante la Edad Moderna, extendiendo el combate contra el Islam al archipiélago asiático:

Aquellos hijos de Castilla sin tierra propia ya que libertar de las garras mahometanas; sin tierra ajena, casi, no vencida por sus heroicos Tercios, tuvieron que ensanchar el mundo para encontrar espacio donde proseguir sus titánicas empresas y llegaron a estos últimos confines por senderos solo conocidos del Sol. ${ }^{43}$

A continuación, los fácilmente digeribles versos del Romancero Filipino desgranaron las adversidades y perfiles épicos que marcaron el viaje de Magallanes y Elcano:

a la Corte voy de España, ¡adiós, Portugal, adiós!

He de llegar a las Indias

siguiendo el curso del sol

y allá por donde se pone

franco paso hallaré yo:

cuando pregone la Fama

realizada tal misión

\footnotetext{
${ }^{42}$ Serie Guerra, Subsección Orden Público, Legajo 8, rollo 1747 (rollo 33), PNA.

${ }^{43}$ Manuel Romero Aquino, Romancero Filipino (Manila: Tipolotografía de Chofré y C. a , 1892), VII. Se puede consultar una versión de esta obra en la Biblioteca Digital Hispánica, URL: http://www.bne.es/.
} 
e ilumine extraña tierra

de esa gloria el resplandor

los que hoy, tan sin razón suya,

me niegan aún la razón ${ }^{44}$

Es Juan Sebastián Elcano

Maestre obscuro poco antes,

$\mathrm{Y}$ al reflejar su grandeza

Truécase el nauta en magnate:

Argente globo terráqueo

por escudo de armas dale,

llenando para más timbre

sus fajas ecuatoriales

mote glorioso que envidian

los más altivos linajes,

diciendo, para su asombro,

a las futuras Edades

que al ir los dos de este a oeste

siguiendo rumbos iguales,

uno, en su eterno camino,

otro, teniendo que hallarle,

rodeando nuestro mundo

él y el Sol fueron rivales

y a la par los dos irradian

resplandores semejantes. ${ }^{45}$

En el caso de la obra de José de Alcázar titulada Historia de los dominios españoles en Oceanía, autorizada en 1895, su dedicatoria inicial al Arzobispo de Manila resultó sintomática:

\footnotetext{
${ }^{44}$ Romero Aquino, Romancero Filipino, 14.

${ }^{45}$ Romero Aquino, Romancero Filipino, 200.
} 
Un libro dedicado a difundir la enseñanza de las glorias de España y los grandes servicios de las órdenes monásticas en el Archipiélago, no debe ser homenaje sino al sabio e ilustre varón que hoy dirige, por fortuna de todos, la Iglesia filipina. ${ }^{46}$

Su valoración de la tarea desplegada por las órdenes religiosas intentó neutralizar desde la escuela los ataques que los frailes estaban sufriendo a manos de los nacionalistas filipinos y los republicanos peninsulares..$^{47}$ El prologuista de la obra, Miguel de Liñán y Eguizábal, reconoció abiertamente la necesidad de controlar las escuelas de las colonias: «La enseñanza elemental, piedra que sirve de base para superiores conocimientos, es en Filipinas, como en todas partes, materia importantísima, que mal puede gallardear el edificio, si los cimientos pecan de débiles o mal trabados» ${ }^{48}$ Más religión y más patria desde la escuela eran los antídotos que se proponían en esta obra para evitar que los cimientos mencionados fuesen zarandeados. ${ }^{49}$

\footnotetext{
${ }^{46}$ Publicada en Manila, en la Imprenta de D. J. Atayde y Compañía, en 1895. Se puede consultar una versión de esta obra en la Biblioteca Digital Hispánica, URL: http://www.bne.es/. Su autor había sido diputado y desempeñaba el puesto de Gobernador Civil de la provincia filipina de Bulacán. El Arzobispo de Manila en el momento en el que se publicó la obra era Bernardino Nozaleda.

${ }^{47}$ Para conocer en profundidad los perfiles de este conflicto, Manuel Sarkisyanz, Rizal and Republican Spain and other Rizalist Essays (Manila: National Historical Institute, 1995); Luis Ángel Sánchez Gómez, Un imperio en la vitrina. El colonialismo español en el Pacífico y la Exposición de Filipinas de 1887 (Madrid: CSIC, 2003); Benedict Anderson, Bajo tres banderas. Anarquismo e imaginación anticolonial (Madrid: Akal, 2008); María Dolores Elizalde Pérez-Grueso (ed.), Repensar Filipinas. Política, Identidad y Religión en la construcción de la nación filipina (Barcelona: Bellaterra, 2009); John David Blanco, Frontier Constitutions. Christianity and Colonial Empire in the Nineteenth-Century Philippines (Berkeley: University of California Press, 2009); Roberto Blanco Andrés, Entre frailes y clérigos. Las claves de la cuestión clerical en Filipinas (1776-1872) (Madrid: CSIC, 2012); Juan Antonio Inarejos, «El republicanismo y la reforma del vínculo colonial con Filipinas», en Experiencias republicanas en la Historia de España, ed. Juan Sisinio Pérez Garzón (Madrid: La Catarata, 2015), 159-182; M. ${ }^{a}$ Dolores Elizalde y Xavier Huetz de Lemps, «Un singular modelo colonizador: el papel de las órdenes religiosas en la administración española de Filipinas», Illes i Imperis 17 (2015): 185-220, y, de los mismos autores, «Poder, religión y control en Filipinas: Colaboración y conflicto entre el Estado y las órdenes religiosas, 1868-1898», Ayer 100 (2015): 151-176.

${ }^{48}$ José de Alcázar, Historia de los dominios españoles en Oceanía (Manila: Imprenta de D. J. Atayde y Compañía, 1895), prólogo.

49 Junto a estas soluciones José de Alcázar también subrayó la importancia de canalizar una corriente de emigración peninsular hacia el archipiélago: «Falta ahora que algún Ministro de Ultramar fije su atención en la necesidad de colonizar a Filipinas, y que estudie y plantee una legislación encaminada a torcer hacia estas regiones tan ricas por su suelo, la funesta emigración española a la América del Sur y a la Argelia francesa», Historia de los dominios españoles en Oceanía (Manila: Imprenta de D. J. Atayde y Compañía, 1895), 189.
} 
Esta vuelta de tuerca que se aplicó a los libros de texto para aquilatar los parabienes de la colonización llevó a denegar la solicitud presentada en 1896 por Eduardo Martín de la Cámara (hijo) para que sus Cuentos fuesen repartidos como premio en las escuelas públicas filipinas. El dictamen del secretario de la Comisión que examinó la obra, presentada el mismo año que estalló el primer levantamiento contra la metrópoli, fue lapidario:

El quinto, Gibraltar (nombre de un gorrión) tiene algo de chiste, pero nada más. Consiste este en que maneja bastante bien la parte histórica y legal del famoso peñón, que hace aplicable al gorrión del cuento [...] La cuestión de ambos puntos de controversia la resuelve el autor diciendo: que el peñón de Gibraltar, lo mismo el gorrión, no debe ser de ingleses ni de españoles sino del mundo; y al efecto suelta el gorrión al aire libre. No hay otra máxima moral..$^{50}$

Un libro que albergaba un cuento que proponía que Gibraltar se emancipase, aunque fuese de Gran Bretaña, no era la mejor moraleja para las autoridades insulares en una fecha tan sensible como 1896. Precisamente los libros de texto y auxiliares habían constituido una pieza más de la arquitectura educativa diseñada para combatir desde el nivel capilar escolar las tendencias reformistas o emancipadoras, por entonces ya explicitadas abiertamente en el archipiélago asiático a través de distintos canales que intentaron sortear los órganos de censura como la literatura, la prensa, las movilizaciones o las asociaciones clandestinas.

\section{A MODO DE CONCLUSIÓN}

Las autoridades coloniales desplegaron en Filipinas un amplio abanico de mecanismos de control social en el ámbito económico, político, religioso y social. La esfera educativa no fue una excepción. El contenido y enfoque de las asignaturas de historia recogidas en la reforma de la Instrucción Primaria de Filipinas de 1863 así lo corrobora. Esta razón explica el férreo control y la censura de los libros de texto destinados a la

\footnotetext{
${ }^{50}$ Serie Guerra, Subsección Orden Público, Legajo 8, rollo 1747, PNA. Este dictamen fue emitido el 5 de mayo de 1896 por fray Marcos Laynez, del Colegio de San Juan de Letrán de los dominicos.
} 
enseñanza primaria y secundaria, similar a la vigilancia que los religiosos dedicaron a seleccionar a los futuros maestros, cuestión poco explorada que también reclama un estudio en profundidad.

Además, esta reforma educativa también abrió enormes horizontes de enriquecimiento económico a través del negocio de la elaboración y venta de los libros de texto destinados a las instituciones educativas filipinas, encuadrados en la tradición historiográfica liberal conservadora. El caso de Manuel Ibo Alfaro resultó paradigmático: sus obras gozaron de varias ediciones y fueron autorizadas para ser introducidas en la colonia y declaradas libros de texto a lo largo de varias décadas. Desde el punto de vista ideológico, su interpretación de la historia de España y del catolicismo resultó del agrado de las celosas órdenes religiosas, allende su contribución a la socialización escolar de discurso nacionalista español, otro mecanismo de control social. En el plano pedagógico, la didáctica de la historia desplegada en las aulas estuvo marcada por su rigidez, el predominio de la memorización de datos y fechas señaladas de la mitología nacionalista y la hegemonía del libro de texto auxiliado por algún cuadro sinóptico.

Junto a las obras específicas para Filipinas, las autoridades gubernamentales también autorizaron un listado complementario de obras históricas, pedagógicas o patrióticas que pudieron ser utilizadas como manuales escolares en todas las provincias ultramarinas. No obstante, además de la censura, la difusión de estas obras se vio entorpecida por dificultades adicionales como los problemas de abastecimiento de las librerías filipinas a causa de la distancia y los desfases marcados por las comunicaciones. Finalmente, durante el tramo finisecular, cuando arreciaron las protestas contra el dominio peninsular a través de canales que consiguieron sortear la plúmbea censura, las autoridades coloniales apoyaron la distribución como manuales escolares de una serie de obras de carácter patriótico que ensalzaron la obra colonizadora de la metrópoli. Desde la escuela se intentaron neutralizar los ataques que los frailes sufrieron a manos de los nacionalistas filipinos y los republicanos peninsulares. En suma, los libros de texto de historia y las obras auxiliares se convirtieron en una pieza esencial de un sistema educativo que fue instrumentalizado para combatir desde el nivel capilar escolar las tendencias reformistas o abiertamente emancipadoras del último tercio del siglo XIX. 


\section{Nota sobre el autor}

Juan Antonio Inarejos Muñoz es Licenciado en Historia (premio extraordinario) y Doctor en Historia Contemporánea por la Univ. de Castilla-La Mancha (mención europea). Ha sido becario predoctoral F.P.U. en la Universidad de Castilla-La Mancha (2003-2006) y becario postdoctoral en L'École des Hautes Études en Sciences Sociales de París (2007-2009). Entre los años 2009 y 2013 fue investigador Juan de la Cierva y JAE-Doc en el Instituto de Historia del CSIC. Desde 2013 es profesor en la Universidad de Extremadura. Es autor de distintos trabajos centrados en el liberalismo y el colonialismo decimonónico español y el tratamiento que ha recibido en las normativas educativas y los libros de texto. Sus últimas monografías se titulan Intervenciones coloniales y nacionalismo español. La politica exterior de la Unión Liberal y sus vínculos con la Francia de Napoleón III (18541868), Madrid, Sílex, 2010 y Los (últimos) caciques de Filipinas. Las élites coloniales antes del desastre del 98, Granada, Comares, 2015.

\section{REFERENCIAS}

Alcázar, José. Historia de los dominios españoles en Oceanía. Manila: Imprenta de D. J. Atayde y Compañía, 1895.

Alonso Álvarez, Luis. «La Administración española en las islas Filipinas, 15651816. Algunas notas explicativas acerca de su prolongada duración». En Repensar Filipinas. Política, Identidad y Religión en la construcción de la nación filipina, editado por M. ${ }^{a}$ Dolores Elizalde Pérez-Grueso, 79-117. Barcelona: Bellaterra, 2009.

Alzona, Encarnación. A history of education in the Philippines, 1565-1930. Manila: Universidad de Filipinas, 1932.

Anderson, Benedict. Bajo tres banderas. Anarquismo e imaginación anticolonial. Madrid: Akal, 2008.

BARRANTES, Vicente. La instrucción primaria en Filipinas, desde 1596 hasta 1868. Madrid: Imprenta La Iberia, 1869.

BAzACo, Evergisto. Escuelas normales y de enseñanza media en Filipinas. Manila: Imprenta de la Universidad de Santo Tomas, 1953.

Bazaco, Evergisto. History of Education in the Philippines. Manila: Universidad de Santo Tomás, 1953.

Benito Argáiz, Inmaculada. «Una aclaración necesaria en la bibliografía del escritor cerverano Manuel Ibo Alfaro (1828-1885)». Berceo 132 (1997): 7-28.

Blanco, John David. Frontier Constitutions. Christianity and Colonial Empire in the Nineteenth-Century Philippines. Berkeley: University of California Press, 2009. 
Blanco Andrés, Roberto. Entre frailes y clérigos. Las claves de la cuestión clerical en Filipinas (1776-1872). Madrid: CSIC, 2012.

Bravo, Julián Tomás (ed. lit.). Cuentos tradicionales y fantásticos: narrativa menor, artículos periodísticos, ensayos históricos y relatos breves de Manuel Ibo Alfaro. Logroño: Universidad de La Rioja, 2000.

Caulín Martínez, Antonio. «El mandato de Carlos María de la Torre (1869-1871): apoyo y oposición al primer gobernador enviado por la Gloriosa». En El Lejano Oriente Español: Filipinas (siglo XIX), 355-366. Sevilla: Cátedra General Castaños, 1997.

Celdrán Ruano, Julia. Instituciones Hispanofilipinas del siglo XIX. Madrid: MAPFRE, 1994.

Cirujano Marín, Paloma, Juan Sisinio Pérez Garzón y Teresa Elorriaga Planes. Historiografía y nacionalismo español (1843-1868). Madrid: CSIC, 1985.

Concepción, Grace Lisa Y. «The Filipino primary school teacher and the shaping of colonial society in 19th century Luzon». International Journal of the Humanities 9, no. 6 (2012): 233-244.

- «Disciplinary Cases of Filipino Teachers in the Late 19th Century». Social Science Diliman, January-June 10, no. 1 (2014): 1-27.

Elizalde Pérez-Grueso, M. ${ }^{a}$ Dolores (ed.). Repensar Filipinas. Politica, Identidad y Religión en la construcción de la nación filipina. Barcelona: Bellaterra, 2009.

- Entre España y Filipinas: José Rizal, escritor. Madrid: AECID/Ministerio de Asuntos Exteriores y de Cooperación, 2011.

Elizalde, M. ${ }^{a}$ Dolores y Xavier Huetz de Lemps. «Un singular modelo colonizador: el papel de las órdenes religiosas en la administración española de Filipinas». Illes i Imperis 17 (2015): 185-220.

- «Poder, religión y control en Filipinas: Colaboración y conflicto entre el Estado y las órdenes religiosas, 1868-1898». Ayer 100 (2015): 151-176.

Escuela Normal de Manila. Elementos de pedagogía para uso de los maestros de instrucción primaria de las Islas Filipinas. Manila: Tipo-litografía de Chofre y Cía, 1890.

Fox, Frederick. «Primary education in the Philippines, 1565-1863». Philippine Studies 13, no. 2 (1965): 207-231.

Gatmaitan, Magno. The Life and Writings of Marcelo Hilario del Pilar. Manila: Historical Conservation Society, 1987.

Goujat, Hélène. Réforme ou Révolution? Le projet national de José Rizal (18611896) pour les Philippines. Paris: Éditions Connaissances et Savoirs, 2010.

Hidalgo Nuchera, Patricio. Encomienda, tributo y trabajo en Filipinas (15701608). Madrid: Polifemo, 1995.

Ibo Alfaro, Manuel. Compendio de la Historia de España. Madrid: Establecimiento tipográfico de M. P. Montoya y Compañía, 1863, ed. 1884. 
- Resumen de la Historia de España. Madrid: Establecimiento tipográfico de los Sres. Martínez y Bogo, 1863.

- Compendio de la Historia Universal. Madrid: Librería de la Viuda de Hernando y C. ${ }^{a}, 1891,6 .^{a}$ ed.

INAREJos MuÑoz, Juan Antonio. Intervenciones coloniales y nacionalismo español. La política exterior de la Unión Liberal y sus vínculos con la Francia de Napoleón III (1854-1868). Madrid: Sílex, 2010.

— «El republicanismo y la reforma del vínculo colonial con Filipinas». En Experiencias republicanas en la Historia de España, editado por Juan Sisinio Pérez Garzón, 159-182. Madrid: La Catarata, 2015.

- «La prensa decimonónica filipina: de la censura a soporte revolucionario». En Redes de comunicación: la prensa en el mundo hispánico, coordinado por Henriette Pratz, 199-212. Berlín: Frank and Timme, 2016.

Isabel, Carlos. «El Plan de Instrucción Pública para Filipinas de 1863 y sus orígenes en la legislación educativa española». Revista Filipina 2, no. 1 (2014): 25-36.

Jiménez, Teófilo. Compendio de Historia de España arreglado para la Instrucción Primaria. La Habana: Minerva, 1884.

Lafuente, Modesto. Historia General de España desde los tiempos más remotos hasta nuestros días. Discurso preliminar. 1850-1858. Edición de Juan Sisinio Pérez Garzón, Pamplona: Urgoiti, 2002.

Martin, Dalmacio (ed.). A century of education in the Philippines (1861-1961). Manila: Philippine Historical Association, 1980.

Meany, James J. «Escuela normal de maestros». Philippine Studies 30, no. 4 (1982): 493-511.

Molina, Antonio M. «Filipinas». En Historia de la Educación en España y en América. Volumen 3. La educación en la España contemporánea (1789-1975), coordinado por Buenaventura Delgado Criado, 508-513. Madrid: Fundación Santa María, 1993.

Osias, Camilo. Education in the Philippine Islands under the Spanish regime. Manila: Philippine Education Company, 1917.

Phelan, John. The Hispanization of the Philippines. Spanish Aims and Filipino Responses, 1565-1700. Madison: The University of Wisconsin Press, 2011, 1. ${ }^{\text {a }}$ ed. 1959.

RAFAEL, Vicente L. Contracting Colonialism: Translation and Christian Conversion in Tagalog Society Under Early Spanish Rule. Durham: Duke University Press, 1993.

- The Promise of the Foreign: Nationalism and the Technics of Translation in the Spanish Philippines. London/Durham: Duke University Press, 2005.

Romero Aquino, Manuel. Romancero Filipino. Manila: Tipolotografía de Chofré y C. ${ }^{\mathrm{a}}, 1892$. 
SaRkisyanz, Manuel. Rizal and Republican Spain and other Rizalist Essays. Manila: National Historical Institute, 1995.

SÁnchez Gómez, Luis Ángel. Las principalías indígenas y la administración espanola en Filipinas. Madrid: Universidad Complutense, 1991.

- Un imperio en la vitrina. El colonialismo español en el Pacífico y la Exposición de Filipinas de 1887. Madrid: CSIC, 2003.

Scotr, William Henry. Barangay: Sixteenth-century Philippine culture and society. Quezon City: Ateneo de Manila University Press, 1997. 